\title{
How do grammatical patterns emerge? The origins and development of the English proper noun modifier construction
}

\begin{abstract}
This paper studies the emergence of a grammatical pattern, the proper noun modifier construction shown in the Obama administration, an Edinburgh restaurant. The only dedicated historical corpus study by Rosenbach $(2007,2010)$ is limited in terms of time depth and data included, and suggests that only proper noun modifiers denoting places such as Edinburgh are found in the early $17^{\text {th }}$ century. Using corpus data that span the full history of English, we trace the construction back to two Old English precursors, genitival modifiers without inflectional marking, e.g. Jericho feldes 'the fields of Jericho' and compounds, e.g. Easter afen 'Easter eve'. We combine macro-level visualisations of distributions and qualitative micro-analyses to show how these source constructions developed into the present-day English construction. The development defies simplistic views grammatical change, but illustrates that grammatical patterns develop out of multiple sources under the influence of a multiplicity of factors. New patterns only emerge gradually and exploit existing ambiguities in the language.
\end{abstract}

\section{The history of proper noun modifiers ${ }^{1}$}

In her research on the relation between determiner genitives and noun modifiers, Rosenbach (2007, 2010) includes a seminal case study of proper nouns as a special subtype of noun modifiers.

Illustrating the pattern are combinations such as the Bush administration or the Barcelona newspapers (2007: 162). The general argument is that determiner genitives and noun modifiers present a case of constructional gradience. ${ }^{2}$ That is, their defining features include certain overlapping syntactic and semantic properties (cf. syntactic gradience in the sense of Denison 2001, Aarts 2007). This synchronic analysis is complemented by a diachronic hypothesis stating that the two constructions encroach on each other over time, i.e. acquire more overlapping properties. Rosenbach's more specific hypothesis is that this encroaching is semantic and happens along a cline of animacy, see Fig. 1 , with the determiner genitive becoming used with less animate types of nouns and the noun modifier with more animate ones.

human $\mathrm{N}-\operatorname{animal} \mathrm{N}-$ collective $\mathrm{N}$ - temporal $\mathrm{N}$ - locative $\mathrm{N}-\operatorname{common} \mathrm{N}$ determiner genitive $=\Rightarrow \quad<==$ noun modifier

Figure 1. Rosenbach's diachronic claim

\footnotetext{
${ }^{1}$ Even though we use the term proper 'noun' modifier throughout this paper, our searches (using any proper noun as part of the query) also include examples of proper names, e.g. New York.

${ }^{2}$ The term 'construction' is used in a pre-theoretical way in this paper as it was by Rosenbach, with a meaning equivalent to "morphological or syntactic unit" (Rosenbach 2006: 49) or 'grammatical pattern'.
} 
Rosenbach finds supporting evidence for this diachronic hypothesis in a corpus analysis of proper noun modifiers (PNMs) in the British English news section of the ARCHER corpus. ${ }^{3}$ In this analysis, she tracks PNMs classified according to animacy type, distinguishing 'human', 'collective', 'temporal', 'locative' and 'other', from 1650 to 1999. She finds that locative PNMs are attested in the very first 50 year period (1650-1699) and temporal and collective ones from 1700-1749, but human PNMs from 1900-1949 only. This confirms her claim of diachronic expansion of the PNM construction in accordance with the animacy cline. PNMs denoting a location are the most frequent type in all periods, though from 1900-1950 the proportion of collective and human PNMs increases. Though it provides important first insights into the diachrony of PNM construction, the corpus study is constrained in several ways. Because Rosenbach's main point of interest is the gradience between PNM and determiner genitive, she excludes certain sets of PNMs that are not in the envelope of variation, notably fixed expressions, e.g. Sunday morning, and onomastic NPs that constitute a proper name as whole, e.g. York Minster, Hampton Court. ${ }^{4}$ Both of these are classed as 'lexicalisations'.

Secondly, Rosenbach limits her investigation to the news section of ARCHER because this is a genre in which PNMs are particularly prolific in present-day English. Finally, while there are comments on certain earlier phenomena, the empirical analysis does not go further back than 1650, the earliest data point in the ARCHER corpus. The study hence suggests that pre 1650, PNMs, if they are present at all, are restricted to locative ones. Our aim in this paper is to empirically investigate the full history of PNMs with a different purpose, tracing the origin and development of this construction. We expect PNMs to be much older and a wider range of types to be present in older data. We believe that the focus on animacy, which has been shown to play a key role in the expansion of the determiner genitive (Rosenbach et al. 2000; Rosenbach 2002, 2007), and possible variation with the determiner genitive in Rosenbach's study, detracted from the distinctiveness of the PNM construction and its development. Our overall interest, as historical linguists, is what the development of this particular construction can teach us about grammatical change and the development of new constructions, and how best to study them.

We therefore substantially extend the data looked at by Rosenbach in multiple ways. Firstly, we look at data prior to 1650, going as far back as the Old English period, in which we find examples of PNMs and their likely precursors. Our data is not restricted to a particular genre. We use various multi-genre corpora to cover the full history of the construction. For Old English, we use the 1.5 million words York-Toronto-Helsinki Parsed Corpus of Old English Prose (YCOE). For Middle and early Modern English, we primarily rely on corpora from the Penn family, the Penn Parsed Corpora

\footnotetext{
${ }^{3}$ A Representative Corpus of Historical English Registers (1600-1999), for more information see http://www.projects.alc.manchester.ac.uk/archer/.

${ }^{4}$ See Rosenbach (this issue) for a very helpful discussion on the objectives of gradience and variation studies, as opposed to 'theoretical linguistic' studies.
} 
for Middle English (PPCME2, 1150-1500, 1.2 million words) and Early Modern English (PPCEME, 1500-1710, 1.7 million words). The choice of these particular corpora is motivated by the necessity of having reliable part-of-speech tagging in order to identify sequences of proper noun + common noun. The trade-off from using these corpora is that the numbers of tokens, though plenty for identifying trends across time (Section 3), are small when it comes to making more detailed observations (e.g. Section 2.3 and 2.4). For this reason, we collect additional examples for Middle English from the nontagged Innsbruck Middle English Prose Corpus (Sampler) (IMEPCS). For the late Modern and Present-day English periods we use the much larger Corpus of Historical American English (COHA, 400 million words, covering 1810-2010), with random samples taken from the 1850s and 2000s subperiods. These data serve to confirm the validity of Rosenbach's findings based on British news section of ARCHER and to provide comparable data sets in the context of this study. Because the collection of the samples differs for the different periods and corpora, we provide a more detailed discussion of the sample collection for each of the periods at the start of the relevant sections.

Secondly, we include various types of data excluded by Rosenbach. Certain names, which Rosenbach excludes as lexicalised, appear to be particularly relevant for the development of the PNM construction as they go far back in time, e.g. the name York Minster goes back to the Middle Ages at least. We also include data in which the status of the proper noun $(\mathrm{PN})$ as modifier is more controversial. The first type are examples such as Sunday morning, Monday evening, in which one could question whether the PN Xday is a modifier or whether the more precise time expressed by the second noun evening, morning is a specifier. In actual corpus examples, this decision is often impossible to make, which is why we are including all such examples. The second type are examples such as Reading town, Jordan river, in which the second noun provides a hyperonymic classification of the PN. Here one option is to exclude them as cases of apposition. However, the presence of examples such as Thames river and Thames mouth shows that the two nouns are not necessarily equivalent; which is why we retain them. ${ }^{5}$

Thirdly, in the analysis, we do not only code for animacy types. We include two other factors which emerged as relevant from the historical data: (1) We annotate the head nouns (HN) for three semantic types, 'place', 'time' and 'other'; (2) We mark whether the whole NP is a proper name or not, distinguishing onomastic vs. non-onomastic NPs. We explain how we operationalise this factor in Section 3. We also added further types of PNMs beyond the types distinguished by Rosenbach when relevant for our understanding of the development of PNMs.

The discussion in this article divides into two main parts answering two different questions: What is the origin of the PNM construction (Section 2) and how do(es) the source construction(s) develop into the PDE PNM construction described by Rosenbach and others (Section 3). Rather than

\footnotetext{
${ }^{5}$ Examples that we did deem to be genuine cases of apposition involve the combination of a personal PN + a common noun giving the person's title, see Section 2.1 for further discussion of these examples.
} 
presenting a chronological discussion, we start with the findings of the quantitative and qualitative analysis of the Middle and early Modern English data (henceforth ME and EMoE), which show straightforward precursors to the PNMs discussed by Rosenbach (Section 2.1). These data are taken as starting point for the qualitative exploration of a sample from Old English (OE) (Section 2.2) and micro-analyses of collective PNMs and human PNMs (Sections 2.3 and 2.4 respectively). In Section 3, we provide a quantitative investigation of the development from ME to PDE (Present-day English). We conclude the article by discussing the wider significance of this study in Section 4. We discuss what this study teaches us about the emergence of grammatical patterns and what the implications are for historical linguists setting out to study them.

\section{The origin of proper noun modifiers}

In this section, we trace the PNM construction further back in time, in order to find its historical sources. We start from the situation in ME and EMoE (2.1), which has also been partly covered by Rosenbach, then to move back in time to OE (2.2). We start each section with a discussion of the data collection process.

\subsection{Proper noun modifiers in Middle and Early Modern English}

To analyse PNM usage in ME and EMoE, we primarily look at data sets from the PPCME2 and PPCEME. The structure searched for was any element tagged as proper noun directly followed by an element tagged as common or as proper noun. The tag sequence proper noun + proper noun appeared to be used in cases where both elements together functioned as a proper name, e.g. Fleet street, Yorke shire, Easter day, Advent Sunday and was therefore not taken as a judgement call on the second noun in its own right (e.g. street as such is a common noun). For ME, additional data were collected from IMEPCS, by querying for combinations of any two forms tagged in PPCME2 as proper noun and noun respectively. Since recall is inevitably compromised by this method, ${ }^{6}$ the additional data are used for qualitative analysis only.

Within the data sets obtained from the Penn corpora, all examples in which one of the elements was tagged wrongly and was in fact not a (proper) noun were excluded in a first step. In a second step, we sorted out one further set of examples in which the relation between PN and $\mathrm{HN}$ is arguably different from a modifier-head relation. These are examples of the kind William bishop of Hely, Etheldredus duke of Mercia, Aurilambros kyng and John Baptist, in which the PN denotes a person and the second element provides a title. We judged the relation between PN and HN to be one of apposition rather than modification. In contrast to potential cases of apposition with other types of PNs, there is no evidence of variation of the kind Thames river vs. Thames mouth affecting the second

\footnotetext{
${ }^{6}$ That is, we could only retrieve from IMEPCS the PNM tokens whose PN and HN also occur in PPCME2 with the proper tag and with the same spelling.
} 
noun. In addition, the second element here can function as a noun phrase (NP) in its own right, sometimes with its own internal modification, e.g. in William bishop of Hely and Cambises sone unto Cirus 'Cambyses son of Cyrus', made more specific by the addition of postmodification. In this way, the original data sets were narrowed down to $162 \mathrm{ME}$ and $378 \mathrm{EMoE}$ examples that can be said to contain a PN modifying a HN. ${ }^{7}$

The PNMs in the data sets were then arranged into animacy types, which we labeled 'human', 'collective', 'time', 'place', and 'other' (see Table 1). For 13 examples, it was not possible to pin down the referent of the PN; these are marked as '?'. We decided to add one new type, 'religious feast', applying to PNs such as Easter, Christmas, All Hallows, Ascension. Within the limitations of Rosenbach's animacy types, these PNs could arguably be grouped under 'time' as they denote an event taking place at a particular point in the year or under 'other'. We separated them out because the temporal aspect is (only) part of their semantic structure and because the group is so prominent in the early data. In eight cases, it was not clear whether the PNM referred to a collective or a place, e.g. Cambridge as reference to the university or the city (see Section 2.3), and we marked them as vague (collective/place) in Table 1.

\begin{tabular}{|l||l|l|l|l|l|l|}
\hline & ME & ME (pmw) & ME \% & EMoE & EMoE (pmw) & EMoE \% \\
\hline human & 0 & 0 & & 15 & 8.8 & $4.0 \%$ \\
\hline collective/place & 0 & 0 & & 8 & 4.7 & $2.1 \%$ \\
\hline time & 11 & 9.2 & $6.8 \%$ & 123 & 72.4 & $32.5 \%$ \\
\hline place & 58 & 48.3 & $35.8 \%$ & 206 & 121.2 & $54.5 \%$ \\
\hline religious feast & 87 & 72.5 & $53.7 \%$ & 19 & 11.2 & $5.0 \%$ \\
\hline $\boldsymbol{?}$ & 6 & 5 & $3.7 \%$ & 7 & 4.1 & $1.9 \%$ \\
\hline total & $\mathbf{1 6 2}$ & $\mathbf{1 3 5}$ & $\mathbf{1 0 0 \%}$ & $\mathbf{3 7 8}$ & $\mathbf{2 2 2 . 4}$ & $\mathbf{1 0 0 \%}$ \\
\hline
\end{tabular}

Table 1. PNMs in PPCME and PPCEME according to animacy/semantic type

Several observations about PNMs pre 1710 can be made prima facie, bearing in mind that Rosenbach's data contained only locative examples in the 1650-1699 period, while two other types, temporal and collective PNMs were attested in the next period (1700-1749). We see a wider range of semantic types, with all animacy types distinguished by Rosenbach except for 'other' - unless religious feasts are considered as 'other' - already attested before 1710 and PNMs denoting places, times and religious feasts attested also in ME (pre 1500). We will look in more detail at the two types

\footnotetext{
${ }^{7}$ As noted in Section 1, the resulting set contains a range of examples that were (presumably) excluded by Rosenbach on the grounds that the PNMs cannot alternate with an $s$-genitive, viz. those in which the NP as a whole is a proper name, e.g. Penteney Abbey; those in which the second element provides a hyperonymic classification of the proper noun, such as Trente watir 'the river Trent', Reading toun 'the city of Reading', Cranford Parish; and fixed expressions with time PNMs, such as sondaye mornynge.
} 
that are first instantiated in the EMoE data, i.e. collective and human PNMs (Sections 2.3 and 2.4). But as the other PNM types were already common in ME, it follows that if we want to come closer to the origin of these PNMs, we have to go further back in time, widening the investigation to Old English, which is what we will do first.

\subsection{Proper noun modifiers in Old English}

The data collection from the YCOE is more complex in that Old English still had relatively systematic and distinctive case marking on nouns, including proper nouns, and the YCOE includes case marking in the part-of-speech tags. We extracted separate samples for the different possible case markings on the PN resulting in 4 sample sets: proper noun tagged as nominative, accusative or dative all followed by a noun (in any case) as well as a set in which a proper noun not tagged for case was followed by a noun. We are stricto sensu not interested in those examples in which the PN has genitive case marking as this construction was retained in later English, but data for proper noun marked as genitive followed by any noun were extracted for reference (see below).

The data sets in which the PN was marked for nominative, accusative and dative case contained a total of 2,039 usable hits, in which the elements were correctly tagged and PN and following noun formed a single NP. The overwhelming majority of these, all but 6 examples, displayed the same semantic pattern: human (first) name + title, as in Cnut kyning 'king', Eadwold preost 'priest', Leofric eorl 'earl', Sigulf ealdormann 'alderman', Osmund biscop of Searbyrig 'bishop'. In three examples, the second element is a nickname, e.g. Turcytel Myranheafod 'mareshead' or AEpelwerde Stameran 'stammerer' (in the dative). As with the ME and EMoE data, these examples of apposition are excluded from the discussion. The remaining 6 examples (all in the accusative) all come from different manuscripts of the Anglo-Saxon Chronicle in the YCOE. They include three different NPs: eall Angelcyn scypu 'all ships of the Angle nation' (ChronC and ChronD)) / eall Angelcynn scipu (ChronE), ealle Engle peode 'all the Angle nation' (ChronD) and Raculf Menster 'Reculver Minster' (ChronC) / Reculf Mynster (ChronA). These examples are retained for a further analysis.

The data set in which the PN was not tagged for case proved more interesting though not without complications. After an initial clean-up, this set comprised 393 examples. Upon closer inspection, some of these examples appeared not marked for case at all, whereas others had an ambiguous ending. Compare for instance Italia lande and Italian lande 'Italy country', in which the head noun lande was tagged as dative and the PN not tagged for case. Italia appears to be the unmarked form and the -an ending could either be dative or genitive. In other cases such as Gallia cyning, the final - $a$ could be part of the unmarked stem, 'king of Gallia' or it could be a genitive plural ending of Gallie 'king of the Gauls'. There were a small number of examples in which the PN is a saint's name ending in -s, e.g. Sanctus Paulus mynstre 'St Paul's minster', Sanctus Nicolaus portice 'St Nicolas' portico', possibly illustrating the $-s$ less determiner genitive. When looking at the 
reference sample in which the PN is marked as genitive, we do find a larger number of similar examples included there, e.g. Maximianus dagum '(in) the days of Maximianus', Moyses boc 'Moses' book', etc. In fact, the reference sample also contains examples of the ambiguous types described above, ending in - $a$ or - $a$ or other ambiguous final letters. For this reason, we decided to exclude all potentially ambiguous examples from a more detailed analysis. This includes all PNs ending in a final letter/final letters that correspond to a genitive ending (-a, -an, $-e,-e n a,-e s)$.

We are left with a set of examples where there is no confusion and the PN is undoubtedly not morphologically marked for genitive case: Moab lande 'land of Moab', Sinai munte 'mount Sinai', Ponto cyning 'king of Ponto', Elig muynstre 'Ely minister'. To these 53 examples we added 5 of the 6 examples marked as accusative case. Following the procedure just explained, we excluded ealle Engle peode, where the PN ends in $-e$ and could be a genitive ending. This resulted in sample of 58 cases which we can safely assume illustrate the PN $+\mathrm{HN}$ structure we are interested in. With the obvious caveat that this is not necessarily a representative sample of PNMs in the YCOE, the data are valuable as evidence of attestation for individual types of PNMs. Table 2 gives an overview of the semantic types of PNMs in the sample, with diverse examples for illustration. ${ }^{8}$

\begin{tabular}{|l|l|l|}
\hline place & 52 & $\begin{array}{l}\text { Ebron dene 'Ebron valley', Sinai westene 'Sinai desert', Lunden } \\
\text { bisceop 'London bishop', paet Rom gesceot 'the Rome scot' }\end{array}$ \\
\hline human/collective & 4 & $\begin{array}{l}\text { eall Neptalim land 'all the land of (the Tribe of) Naphtali', eall } \\
\text { Angelcyn scypu 'all ships of the Angle nation' }\end{array}$ \\
\hline religious feast & 2 & Easter afen 'Easter evening', pare Easter wucan 'the Easter week' \\
\hline total & $\mathbf{5 8}$ & \\
\hline
\end{tabular}

Table 2. PNMs in the YCOE sample according to semantic type

Our limited data set provides evidence of three semantic types of PNMs. Two types correspond to types for ME, PNs denoting places and religious feasts, which supports our hypothesis that PNMs are in fact a much older phenomenon than suggested in earlier studies. The third type is marked as human/collective. These are singular PNs that refer to a 'group of humans', e.g. a tribe, a nation, an ethnic group. As 'collectives of human entities', they are ambiguous between two of the animacy types.

A closer look at individual examples sheds light on the possible sources for these PNMs. We already noted that there is ambiguity as to whether PNs are marked for genitive case or not. In this unambiguously unmarked set, many examples express a core relation usually conveyed with a

\footnotetext{
${ }^{8} \mathrm{We}$ do not give normalised frequencies because these may not be representative due to the exclusion of ambiguous examples.
} 
genitive, e.g. possession in Naphtali's land ${ }^{9}$ or the Angle nation's ships. In fact, for many of the examples, there are equivalent examples, with a different PN but the same $\mathrm{HN}$, in which the PN is marked as genitive in YCOE, e.g.

(2) Lunden bisecop and Hagusteald biscop vs. Hagestaldes biscop and Hrofeceastre bisceop

(3) Iericho feldum vs. Moabes feldum

(4) Bethleem birig vs. Romes burh

We propose that the problems with applying genitive marking or recognising genitive endings on PNs is one factor leading to PNMs. This is in particular the case for foreign names which do not straightforwardly fit in with the Old English noun declensions (see also Altenberg (1982) on the $-s$ less genitive with foreign names in Section 2.4).

Not all examples fit in with this categorization, though, e.g. Easter afen 'Easter evening' and Rom gesceot 'Rom scot' or 'Rome penny', which is a tax payable to the papal see in Rome (see OED, s.v. Rom-scot). We have no reason to assume that these examples alternate with genitive marked ones; instead they are listed as compounds in dictionaries such as Bosworth and Toller's Anglo-Saxon Dictionary and the OED. Bosworth and Toller, for example, list a number of compound nouns with Easter as first part, e.g. Easteraefen 'Easter evening', Easterdag 'Easter day', Easterfasten 'Easter feast', Eastermonap 'Easter month', etc. We therefore suggest that a second source for PNMs were OE compounds. The religious feast examples all belong to this type. In the case of PNs denoting places or nations/ethnic groups, it seems that unmarked genitival modifiers are the most frequent source, but there are also cases that suggest a compound source. It should be noted that the delimitation of compounds and syntactic groups is as much a problem for OE as it is for PDE. Kastovksy (1992: 362-363) notes that spelling is not a reliable indicator of compound versus phrasal status in OED. The presence of inflectional endings on the first noun can be taken as evidence of phrasal status; however, this does not work for genitive markings as these could occur in so-called 'genitive compounds', e.g. dageseage ‘daisy, lit. day's eye', Sunnandarg 'Sunday'. We found the variants Rome byrig, Romeburg, Romes burh and Romesbyrig in YCOE. The ambiguous morphosyntactic status of proper noun + noun combinations as compounds or phrases, which is a matter of debate for PDE as well (e.g. Breban 2018), may have facilitated the convergence of the two OE sources for PNMs.

Looking at the data from YCOE, we conclude that PNMs are an 'old' feature of the English language that have their origins in two source patterns: PNs unmarked for genitive case and compounds with a PN as first element. The emergence of PNMs is thus connected to larger changes

\footnotetext{
${ }^{9}$ Naphtali is one of the sons of Jacob in the Old Testament and in this particular case Naphtali stands for the tribe made up by his descendants. The fact that Naphtali is both a collective and (originally) a first name adds further complication to its categorisation.
} 
affecting the English language system, most importantly the break-down of the system of nominal inflections, exacerbated by the form of foreign (place) PNs which do not straightforwardly fit in with inflectional paradigms. The possibility to spell compounds as single or separate word forms presented a second reason for the occurrence of 'PN N' combinations, which constitute the structural template of the PNM pattern.

\subsection{The first collective PNMs}

Though there are no unambiguous examples of collective PNMs, such as Rosenbach's FBI in the FBI director, our earlier data include examples that could possibly be analysed as collective PNMs. The YCOE data contain two examples of tribes of ethnic groups, eall Neptalim land 'all the land of (the Tribe of) Naphtali', eall Angelcyn scypu 'all ships of the Angle nation'.

Another likely predecessor to collective PNMs is attested both in the PPCEME and even earlier, in the additional IMEPCS data. These are combinations referring to the institutions of Parliament (Parlement Howse, Parlement mater, parlement robes) and Church (Churche werk, church landes, Church discipline). Both Parliament and Church are also common nouns, and tagging in PPCEME is not consistent nor is it always possibly to determine common/proper noun status for individual examples. We therefore chose to err on the side of caution and did not include examples with Parliament or Church in the figures in Table 1. Nevertheless, they are an indication that certain collective PNMs may have been present well before 1700. In the case of Church, the OED provides examples of what it refers to as 'attributive compound' uses dating back as far as the OE period, Chirche pament 'Church payment' (1455), chirch steuene 'Church teaching' (c1275), eallum cyricgerihtum 'all Church dues' (OE, Wulfstan's Institutes of Polity) and cyricwadan 'Church garments' (OE, Laws of Eðelred II). ${ }^{10}$ These would be further examples of PNMs that go back to what could have been compound forms in $\mathrm{OE}$.

Finally, there are examples found in PPCEME and included in Table 1, such as $a$ Westminster matter (1548) 'a matter for the Court of Justice which sat at Westminster Hall', an Al Sowl Colledge man (1582), Cambridge letters (1630) 'letters while sender was in Cambridge/at Cambridge university', or a Newgate bird (1633) referring to Newgate prison. In all these cases the PN is a physical place/building as well as an institution located there. In most examples the PN is shortened, e.g. Newgate (prison) and/or the place it refers to metonymically stands for the institution, e.g. Westminster meaning 'the Court of Justice' or Cambridge meaning 'Cambridge University'. As such the early examples are superficially the same as the established examples with place PNMs, and we could hypothesise that this vagueness formed a bridge to examples such as FBI director in which the institution is the only possible referent for the PN and the PN is unambiguously collective.

\footnotetext{
${ }^{10} \mathrm{OED}$, s.v. church, n.1 and adj. Compounds $\mathrm{C} 1$ a. The earliest attestation for parliament in the OED dates from c1300.
} 


\subsection{Human PNMs in ME and EMoE: -s less determiner genitives or modifiers?}

The figures in Table 1 show the first examples of human PNMs to be attested significantly earlier than Rosenbach's ARCHER data suggest (after 1900). The situation is complicated, however, by the occurrence of -s less determiner genitives at the time (Altenberg 1982: 45-51, Rosenbach 2002: 205209), making the evidence harder to interpret. The aim of this section is to assess the evidence: are there any genuine examples of human PNMs in our data set?

In his study of the genitive in the 17th century, Altenberg (1982: 45-51) describes the phonetical and morphological conditions in which what he refers to as the 'zero genitive' occurs. Relevant to this discussion, these include human (foreign) PNs ending in -s, e.g. Moses face, Doctour Caius wife, mr Roberts letter, and HNs starting with $-s .{ }^{11}$ There were a number of examples that we considered $-s$ less determiner genitives in PPCEME and excluded as instances of PNMs in Table 1. They are ser Antony Knevett servand (1553/9), master Dolman howsse (1553/9), my Cosine Ison wife (1599/1601), my Cossine Gates house (1599/1601), doctor Bolds dawgther (1582), ye Ld Clare breast (1689/92). Note that not all of these are conditioned phonetically because the PN ends in $-s$ or the HN starts with $-s$ (e.g. servant), but in all cases the relation between PN and $\mathrm{HN}$ involves core genitival relations such as alienable and inalienable possession and kinship. In all examples the possessor PN is a complex phrase. ${ }^{12}$

Rosenbach (2007: 181, see also Rosenbach this issue) points out a different, special set of examples with potential human PNMs, which consist of a saint's name and a $\mathrm{HN}$ denoting a place or a day, e.g. Saint Paules Church, saynt Marke day. They occur alongside examples of the same type in which the PN is a determiner genitive marked with -s, e.g. Seynt Margaretes Day. Rosenbach analyses the examples without $-s$ as lexicalisations of determiner genitives, which as part of the lexicalisation process have lost the genitival $-s$ marking. She concludes that they are not a productive new pattern of PNMs. In this case too, we find similar examples in our PPCEME data set: seynt laurence church (1526), Bartilmewe fayre 'Bartholomew feast day' (1535), S. Laurence chirch (1535/43), sant Margatt parryche (1553/9), sant Margett chyrche (1553/9), sant Austyn parryche (1553/9), sant Thomas of Cantebere day (1553/9), and St. James church (1688/89). Cases where the PN ends in -s, e.g. seynt laurence church and St. James church, can be subsumed under -s less genitives. However, in line with Rosenbach, we note that these examples overall constitute a recurrent type. They have a long pedigree, being particularly common in the IMEPCS data, e.g. in seynt Michell

\footnotetext{
${ }^{11}$ Altenberg (1982: 49) observes that inanimate nouns are in general very rarely marked by the genitive $-s$ in this period and that uninflected place names, e.g. Britain lande, Ister banke, were common in premodifier position. He explains these go back to marked genitives, e.g. OE Themese mupan, or to uninflected appositional combinations, e.g. OE Trenton streame. We agree with Altenberg that this type of examples is a source for place PNMs (Section 2.2), but our analysis treats both cases as genitives in OE, one marked and one unmarked.

${ }^{12}$ In IMEPCS we find more similar examples, which are probably best analysed as morphologically unmarked genitives with foreign names (e.g. Adam body, Noe schyppe) and complex possessor phrases (e.g. Sir Robert Whitingham wyffe or my Lord of Warrewikke men).
} 
mount or our lady-chyrch, where many of the saints' names found also have attested marked genitive forms, as in saynt Mychels mounte, at oure Ladyes fete, Seynt Mathewys day. The alternation between $-s$ marked genitival forms and what is (given the definite article) decidedly a modifier use of the same PN is illustrated in a single passage from the same text in (1):
And on Seynt Kateryns even, in semblable wyse, the seide Maire and Shiref and their brethren [haue vsid] to walke to Seynt Kateryns Chapell within Temple church, there to hire theire evensong; and from evesong to walke vnto the Kateryn halle, theire to be worshipfully receiued of the wardeyns and brethren of the same; and in the halle there to have theire fires, and their drynkyngs, with Spysid Cakebrede, and sondry wynes; the cuppes merelly filled aboute the hous. (IMEPCS)

Examples such as (1) show that these examples cannot simply be subsumed under the determiner genitive in the same way that examples such as ser Antony Knevett servand and master Dolman howsse can, as also argued by Rosenbach.

We, however, disagree with Rosenbach's claim that they are only a restricted and unproductive variant of particular onomastic genitives naming places and feast days. We argue this perception is a result of her narrow definition of PNMs and propose that the examples fit in with the other types of PNMs in our ME data. The recurrent subtype referring to holidays, e.g. Bartilmewe fayre, echoes the prominent pattern with religious feast PNs in ME, which, as we discus in Section 3, all combine with a HN referring to a particular time, e.g. Ester day, the Chrystysmasse weke, Whitsone Eue, Alle Halwyn tyde 'All-Hallows' tide', pe halirode day 'Holy Cross day', etc. In the EMoE data, we see a diversification of the HNs combining with religious feast PNs to include places (Whitsonday farm) and miscellaneous others (my Chrismas dynner, ye Michas pay 'Michaelmas pay'). There is some evidence from EMoE that the saints' name pattern was not restricted to HNs denoting day or place: For (Saint) Catherine, the OED lists Catherine wheel (first attestation $a$ Katharine wheele (1584)), Catherine pear (a Katherine Pear (1641)) and Catherine plum. ${ }^{13}$ The similarities with one of the main patterns for ME mean the saints' name pattern cannot be dismissed as an isolated lexical phenomenon.

Finally, there are examples in our PPCEME set where a determiner genitive reading is ruled out altogether: i.e. a Abraham man / these Abrahom men (1567/8), a King Harry face (1582), the Spracklinge Coat (1624/5), the Sprakling Armes (1624/5), the Sprackling armes (1625/7), ye Ashmole peare (1689/92). The phrase Abraham man, used twice in the same text once with $a$ and once with these, has its own separate entry in the OED, where it is defined as "a beggar claiming to have been

\footnotetext{
${ }^{13}$ OED, s.v. Catherine wheel, n. and OED, s.v. Catherine, n.
} 
released on license from the Hospital of St Mary of Bethlehem in London or a similar institution". ${ }^{14}$ Its origin is not known. King Harry face used with the indefinite article in our example refers to a type of coin. There are several other combinations in which the first name of a king/queen premodifies a common noun denoting a coin in the OED, e.g. the Marie ryall (1565), old harry soveraignes (1615), an old Harry groat (1633). ${ }^{15}$ These examples show that it was at the very least not impossible to use a (title + ) first name PN as modifier well before 1900. In the $17^{\text {th }}$ century, finally, we find examples with a PN consisting of a last name only, Sprackling and Ashmole. ${ }^{16}$ These are the first instances similar to examples like the Bush administration and the Weaver car ('car belonging to the Weaver family') given as prototypical examples of human PNMs in PDE. ${ }^{17}$

All in all, the evidence places the first occurrences of human PNMs at least in the $16^{\text {th }}$ century, and maybe as early as ME, albeit in certain collocational niches. A possible explanation for the large time difference between our and Rosenbach's first examples might be related to different genre-restrictions. Many of the human PN examples are found in texts belonging to the private sphere: e.g. a king Harry face in the diary of Richard Madox, Bartilmewe fayre in a letter from Margaret Roper to her father Thomas More, ye Ashmole peare and the examples with Sprackling in the correspondence of the Hatton and Oxinden families respectively. ${ }^{18}$ This might signal that this specific type of PNM is part of an informal register. Rosenbach restricted her analysis to news texts, in which PNMs feature prominently in PDE, in line with findings that noun modifiers are part of a compressed written style. We agree with Rosenbach that many examples have an onomastic character (naming a day, a place, a coin, a variety of fruit). However, rather than taking this as an indication of a particular lexical status, we will argue in Section 3 that it is an integral part of the proper noun modifier construction.

\section{The emergence of the PDE PNM construction}

In the previous section, we traced back the PNM construction before Late Modern English and identified two possible sources of PNMs in Old English. In this section, we discuss how these first

\footnotetext{
${ }^{14}$ OED, s.v. Abraham man, n. There is also a cant alternative Abraham cove first attested in 1612 (OED, s.v. Abraham, n.)

${ }^{15}$ OED, s.v. Mary, n.1 (and int.) Compounds C1. and OED, s.v. Harry, n.1 Compounds C2 attributive.

${ }^{16}$ With the exception of title + first name, examples with complex names, including first + last name PNMs, appear to be a LMoE innovation, only showing up in our COHA data, and there mainly in the PDE subset. The only complex human PNM in our 1850s sample is the King Charles dog, answering to the title + first name type. In the 2000s data complex human PNMs are common, as in the Benjamin Franklin Bridge or a Pete Townshend excuse. This timing is corroborated by a query on names for streets, bridges and squares, which in COHA first show up with complex human PNMs (other than the title + first name type) in 1867 (Laura Matilda Street) and 1931 (George Washington Bridge, Mark White Square) respectively.

${ }^{17}$ One could note that Sprackling in combination with the head nouns arms and coat refers to 'the Sprackling family' as a collective, in contrast to the later ye Ashmole peare in which the surname refers to a single individual. For reasons of comparability, we follow Rosenbach in classifying all last names as human PNMs. ${ }^{18}$ See the PPCEME webpage on philological information for more details: https://www.ling.upenn.edu/histcorpora/PPCEME-RELEASE-3/.
} 
possible instances of PNMs relate to and developed into the construction as described for PDE by Rosenbach $(2007,2010)$ and Breban (2018) and several articles in this special issue.

To capture the post 1710 stages in the development of the PNM construction, the Corpus of Historical American English (COHA) was queried for any proper nouns preceding a common noun. Specifically, two random 500-hit samples were drawn from COHA, one from the 1850s subsection, and one from the 2000s subsection. After removal of false positives, 308 examples remained for the 1850 s and 325 for the 2000s. These were analysed following the same procedures as for the older data. Knowing these raw figures, as well as the respective corpus sizes and sampling rates, normalised frequencies for the PNM construction can be estimated. Fig. 2 shows the results, revealing an exponential increase in the construction's frequency from LMoE to PDE, much in line with the findings of Rosenbach $(2007,2010)$ for the British news section of ARCHER.

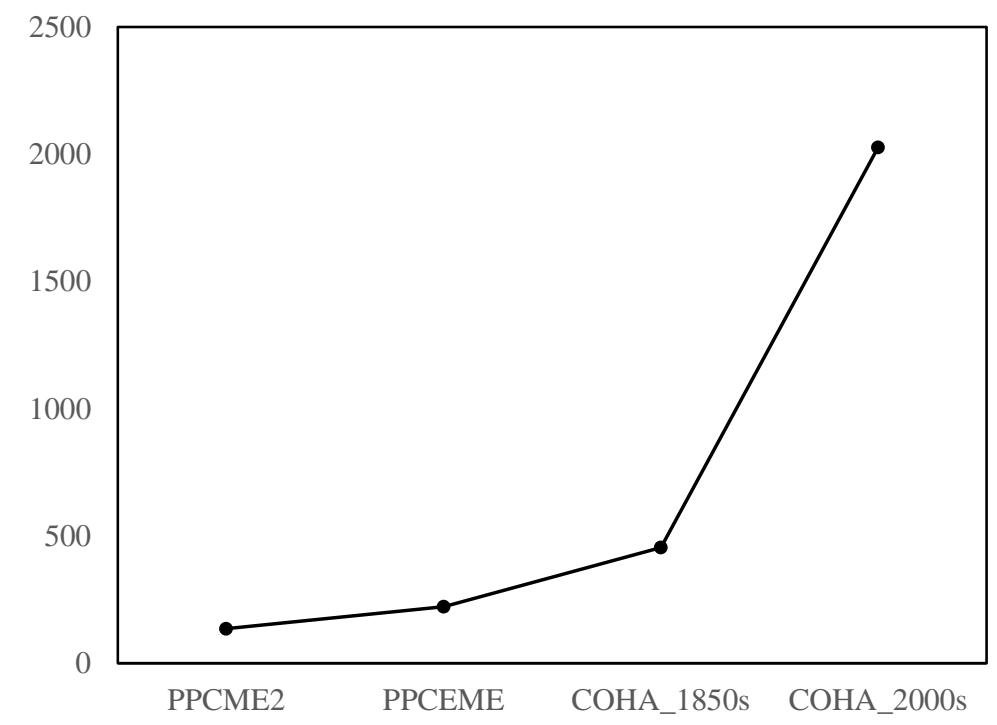

Figure 2. Normalised frequency (per million words) for the PNM construction from ME to PDE, based on PPCEME2, PPCEME and COHA.

Our aim is to arrive at a comprehensive picture of the development of the PDE PNM construction. The discussion so far has shown that animacy is neither the only nor the main factor determining the types of PNMs found or their emergence. Based on the detailed investigation of the historical data, we include three variables in the analysis proposed here. These are semantic type of PNM, semantic type of $\mathrm{HN}$ and the onomastic or non-onomastic status of the NP as a whole (is it a name in its own right or not). The three aspects of PNMs under study are jointly visualised in Fig. 3, which in four panels shows the changing distribution of the PNM construction over different types of PNMs, HNs and NP types. The four panels represent (a) ME (based on the data from PPCME2), (b) EMoE (based on the data from PPCEME), (c) LMoE (based on the 1850s sample from COHA) and (d) PDE (based on the 2000s sample from COHA). On the left-hand side of each panel, the semantic 
types of PNMs are listed (Feast, Time, Other, Collective, Human and Place). On the right-hand side, three semantic types of HNs are distinguished (Time, Other and Place). The size of the data points indicates the relative frequency of each type. The connecting lines indicate attested combinations; the wider the line, the higher the relative frequency of the combination. The colours represent the referential status of the entire NP with red shading indicating the share of onomastic NPs (behaving like a name in their own right) as opposed to yellow for non-onomastic NPs. NPs were analysed as onomastic if they lacked an explicit determiner (e.g. Forbes Magazine or Kansas City), unless they were plural or had a mass $\mathrm{HN}$, in which case the absence of a determiner can just signal indefiniteness (e.g. Alaska king crab with a hearty butter sauce)..$^{19}$ This method of annotating is conservative in assigning onomastic status, since proper names can sometimes have a determiner (e.g. the Chicago Symphony Orchestra, the Hudson River). As such, any red colouring signifies a strong tendency for the type or combination to be associated with onomastic as opposed to non-onomastic NPs. ${ }^{20}$ It needs to be emphasized that both size and colour reflect relative frequency in this type of visualization; if a type or combination is substantially less frequent than (an)other type or combination it is backgrounded irrespective of its absolute frequency. As such these visualisations draw out the most central features and patterns of the PNM construction over time and abstract away from detail. This contrasts with the micro-analytical approach of the qualitative analyses in Sections $2.2-2.4$ which foreground special, infrequent patterns. We include qualitative observations in the following discussion where relevant.

\footnotetext{
${ }^{19}$ Another exception is the type seen in Massachusetts Institute of Technology Nobel Laureate Robert Solow warns against complacency, where the PNM construction (Massachusetts Institute of Technology Nobel Laureate) is itself a modifier to a proper name (Robert Solow). Omission of the determiner is the rule here, but the PNM construction is obviously non-onomastic.

${ }^{20} \mathrm{We}$ also coded for the alternative proxy, i.e. NPs showing any evidence of non-onomastic status. The specific features we took to signal non-onomastic status are presence of a determiner other than the definite article (this includes the indefinite articles but also demonstratives and quantifiers such as some and every), plural marking on the HN (unless the NP referred to a known plural name, e.g. the Maledives), the presence of adjectival modifiers in the NP. The results are in line with the results reported below and will not be separately documented here.
} 
(a) Middle English

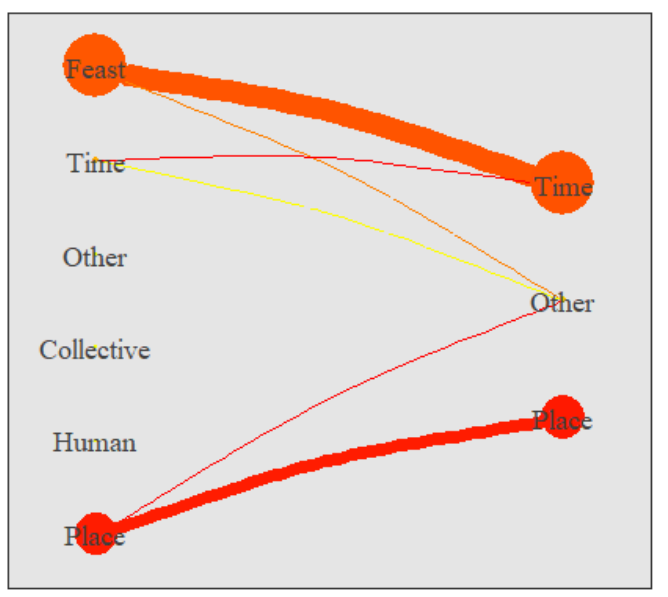

(c) Late Modern English

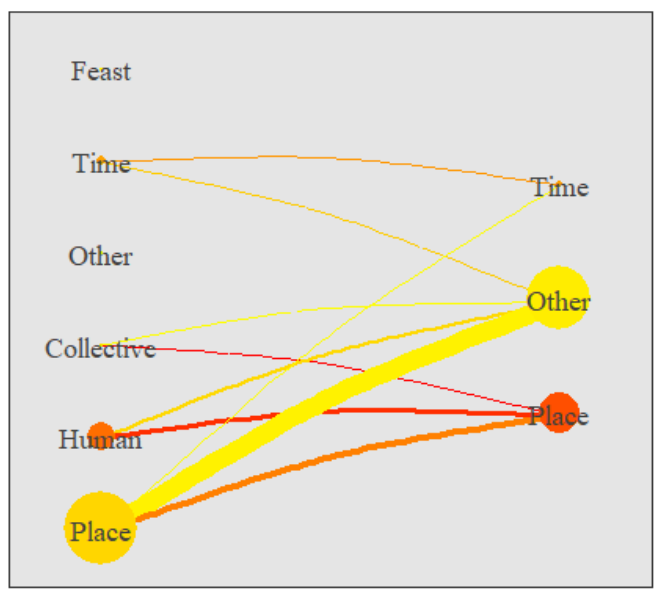

(b) Early Modern English

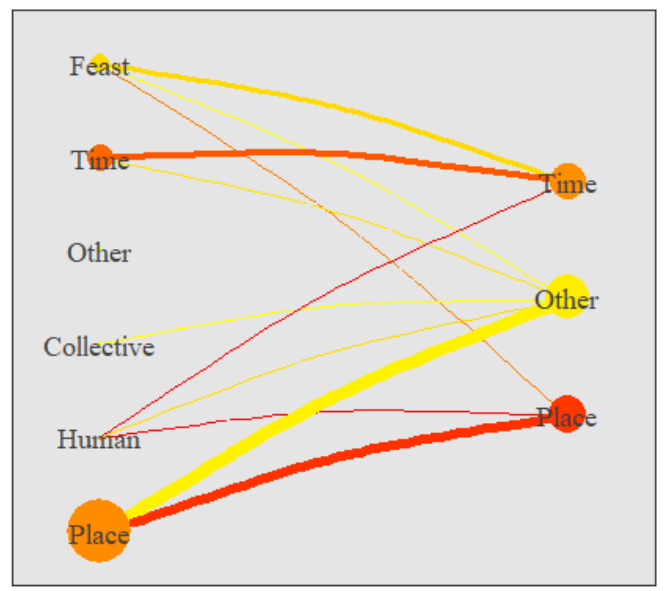

(d) Present-Day English

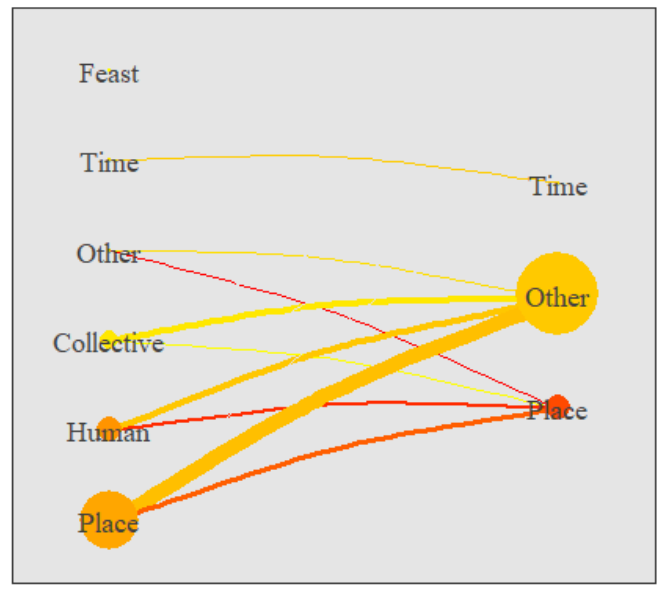

Figure 3. The changing distribution of PNMs over modifier types (left), head types (right), and onomastic (red) vs. non-onomastic (yellow) NPs.

We start our discussion by contrasting panels (a) representing ME and (d) representing PDE. The PDE panel in Fig. 3 (panel (d)) largely matches the description of PNMs in PDE given in the literature. Various types of PNs are attested with place PNs being the most common. The majority of HNs they combine with are 'other' HNs, i.e. not time or place HNs. The main distributional pattern consists of a place, human or collective PNM and a HN that does not refer to time or place. This pattern is yellow to orange indicating that this combination results in both non-onomastic and onomastic NPs. This pattern can be identified with the highly productive PNM construction evidenced in NPs such as an Edinburgh newspaper, the Guggenheim museum, most New England preachers, the Tudor style, a Disney spokeswoman, a former Bill Clinton student, etc. In the remainder we use the 
shorthand 'PDE PMN construction'. In addition, two less prominent patterns show up: There are place, human and other PNMs that combine with mainly place HNs to create new proper names, typically place names, e.g. Boston district, Hudson river, George Washington square. There is a marginal and restricted pattern in which time PNs combine with time HNs, e.g. Monday morning, Christmas day. Note though that this association between time PNs and time HNs is probably less exclusive than the PDE panel of Fig. 3 suggests. Combinations such as Sunday dinner or Christmas present (with 'other' HN) obviously occur. They are just very infrequent relative to the other combination types attested in our sample.

The ME panel of Fig. 3 (panel (a)) is strikingly different. There are two main patterns standing out. At the bottom of the plot, we have place PNs that combine with place HNs to make place names. The data points and line are bright red indicating that the resulting NPs behave almost exclusively like proper names. Examples include Dorset schyre, Flete Strete, Lyndefare cherche 'Lindisfarne church'. The other main pattern, at the top of the plot, are combinations of PNs referring to religious feasts or, less frequently, time with HNs typically denoting time, e.g. Ascension Euen, Candylmas daye, mydwynter tyde. Here, too, the pattern mainly associates with onomastic uses. Assuming that the high degree of distributional segregation between these two patterns justifies treating them as separate constructions, at least for ME, we will refer to these patterns as the "place name' and 'time point' constructions. ${ }^{21}$ It can be noted that the two constructions approximately correspond to the two sources for PNMs suggested above for OE. More precisely, time point constructions are related to those examples identified as OE compounds, while onomastic place constructions appear to mainly (but not exclusively) derive from morphologically unmarked genitives (Section 2.2). This, too, indicates that they were likely separate constructions at some point. These two main constructions show a correspondence to the two peripheral patterns in the PDE panel.

In addition to these two main constructions, there are some instances of place, time and feast PNMs combining with 'other' HNs, e.g. Astyr seruyce 'Easter service', Rome scot, May buttre. Here, the combinations with time and feast PNMs show a stronger tendency towards non-onomastic use. There are more examples of place PNs with 'other' HNs, including some in non-onomastic NPs, in the IMEPCS data, e.g. the London carrier, Paston men or a Normandy byll, but they are rare in comparison with place names. ${ }^{22}$ The subsequent panels show that it is this small area of overlap with non-prototypical uses of both constructions that gains in relative frequency and expands over time to become the core of the PDE PNM construction.

The EMoE and LMoE panels of Fig. 3 (panels (b) and (c)) clearly show this development from the ME to the PDE distributions. The development comes with the following changes: Place and

\footnotetext{
${ }^{21}$ The qualitative data from IMEPCS discussed in Section 2.4 add instances of PNs denoting humans which combine with place and time HNs.

${ }^{22}$ If Church and Parliament are accepted as PNMs (Section 2.3), they would provide a set of examples featuring mainly 'other' HNs as well as some place HNs.
} 
especially time HNs become relatively less frequent, whereas 'other' HNs come to dominate PNM usage. Gains in frequency of PNMs overall are particularly associated with the pattern with 'other' HNs. PNs become more diverse in this pattern, which echoes the findings of Rosenbach. However, PNMs denoting humans gain in frequency before those denoting collectives do. In EMoE and LMoE the pattern with 'other' HNs is found in non-onomastic NPs. However, our data suggest that the pattern becomes more onomastic, making it in this respect more like the ME constructions. There might be a connection with Breban et al. (this issue)'s finding that native speakers associate the PDE PNM construction with a 'naming' relation between PN and HN. Both findings, though pertaining to different aspects of the PDE PNM construction, point to a connection between the construction and the communicative function of naming. Given that this connection is strongly present in the precursor constructions, this could be seen as persistence (Hopper 1991) of the original function in later stages of grammatical development. The ME time point construction is first affected by the diminishing frequency of PNs denoting religious feasts. The remaining time $\mathrm{PN}+$ time $\mathrm{HN}$ pattern then becomes increasingly isolated and less prominent. The ME place name construction remains well-attested and undergoes some blurring of its distributional boundaries as its PNs become more diverse. It is only in the PDE panel that its share decreases.

Finally, it should be remarked that the expansion of the PDE PNM construction as seen in Fig. 3 generalises over loss at the micro-level. The PPCEME sample contains examples with names of foreign countries, such as the Turke Ambasset (1517), the Portugall Bishop (1605), the morroccoe imbassador (1635/39), a pair of China shoes (1685) and the Japan tongue (1685). In PDE ethnic adjectives Turkish, Portuguese, etc. would be used here instead. A quick search in the OED shows first attestations of the adjectival forms in the $16^{\text {th }}$ or $17^{\text {th }}$ centuries (Turkish 1545 , Portuguese 1552 , Chinese 1577, Japanese 1588, Moroccan 1685). As the adjectival forms are largely restricted to names for certain countries and a few cities, e.g. Parisian, in English, the loss is not picked up in Fig. $3 .^{23}$

\section{Concluding discussion: proper noun modifiers and the emergence of grammatical patterns}

The descriptive aim of this article was to extend the diachronic description of the PNM construction beyond the first observations made by Rosenbach (2007, 2010). Rosenbach only looked at data from the $17^{\text {th }}$ century onward, which fitted in with her larger aim of studying the changing variation of determiner genitives and noun modifiers. She projected back from PDE in terms of methodological choices to do with in/exclusion of examples, the selection of a particular genre, and a hypothesis based on her work on English genitive constructions. Taking a much more inclusive approach towards data selection, we uncovered a more extensive and complex diachronic development. Our analysis led

\footnotetext{
${ }^{23}$ In other Germanic language such as Dutch and German, denominal adjectives are more widespread and PNM construction with place names are less frequent (Schlücker 2013, Breban 2018, Ström-Herold \& Levin this issue).
} 
to the identification of two main source constructions in the OE period: the morphologically unmarked genitive modifier and lexical compounds. The first construction was shown to typically occur with (foreign) place PNs, whereas the second construction could occur with any type of PNs (place/human/feast/time/collective). We argued that these two precursor constructions developed largely independently into the place name and time point construction that dominated ME usage of PNMs. The PNM construction as described for PDE gradually emerged starting from overlap between these two constructions, in particular in combinations with non-time and non-place HNs. As far as we can tell from the ME and EMoE evidence, human PNMs had an early collocational link to the time point construction through various saints' holidays (e.g. Our Lady Day). Collective PNMs may have developed from the place construction through metonymically used place names (e.g. Cambridge letters). These innovations increasingly blurred the boundaries between the two ME constructions, and as the area of overlap between them became more prominent, a more unified pattern emerged. The findings are reminiscent of the spread of English complement constructions, which likewise tend to originate from disparate minor patterns (De Smet 2013). Our findings challenge that the historical diversification in the types of available PNMs can be deduced to a gradual extension along the animacy hierarchy, but at the same time also confirm and accommodate several of Rosenbach's observations in a single story. Lexicalised saints' names are argued to be part of a productive pattern. Increased frequency of the PNM construction as a whole, as well as of certain types of PN, are the main changes from LMoE to PDE. The onomastic character noted for the PNM construction in PDE reflects its source constructions. History explains synchrony rather than vice versa.

Our findings concerning the possible precursors and subsequent emergence of the PNM construction have wider implications for the understanding and study of grammatical change. Firstly, they provide further evidence for the ubiquity of multiple sources constructions (De Smet et al. 2015). Multiple source constructions question a simplistic linear development "drawing straight lines between a construction and a single historical ancestor" and can be envisaged as the "blending of clearly distinct lineages" (Van de Velde et al. 2015: 1). This is well-established for phonological and lexical semantic changes but is not recognised as much with regard to changes in morphology and syntax. Secondly, our findings underscore Joseph's (2015) argument that in addition to multiple sources, there is also a multiplicity of factors involved in individual cases of change. Changes are caused by "multiple pressures on some part of a language system" (Joseph 2015: 207). For our case study, we have discussed the break-down and loss of the nominal inflectional system, the difficulty of incorporating foreign names with 'exotic' word forms into the inflectional system, the ambiguous morphosyntactic status of compounds in historical and present stages of English. Changes to noun phrase modification in written texts in Late Modern English have been shown to influence the increase in usage in this period (Rosenbach 2007; Biber \& Gray 2011, 2016). Thirdly, our findings support views of grammatical change as gradual emergence of constructions (e.g. Hopper 1987, De Smet 2013). Our case study shows the gradual adding to and gradual distributional crystallisation of 
the PNM construction. The emergence of a new grammatical pattern happens gradually within the language system in place exploiting ambiguities. We hence agree with the discussion in Traugott \& Trousdale (2010: 23) that change is only radical if we look at the 'macro-effects', represented quite strikingly by juxtaposing the ME and PDE panels in Fig. 3. The overall picture that emerges from our case study is that grammatical patterns develop out of multiple sources, influenced by a multiplicity of factors, against the background of the language system. New patterns emerge gradually and exploit existing ambiguities. The complexities of these and other developments warn against imposing generalizations based on (synchronic) theorising on historical processes (Anderson 2016; Cristofaro 2017). The study of such changes requires a data-driven methodology that casts the net wide in terms of data selection and combines frequency analysis with qualitative micro-level analysis to arrive at a comprehensive understanding.

\section{References}

Data resources

Bosworth and Toller: Sean Christ and Ondřej Tichý. 2010. Online edition of An Anglo-Saxon Dictionary, edited by Joseph Bosworth and T. Northcote Toller. Faculty of Arts, Charles University Prague. (http://bosworth.ff.cuni.cz/about).

COHA: Davies, Mark. 2010-. The Corpus of Historical American English: 400 million words, 18102009. http://corpus.byu.edu/coha/.

OED: Oxford English Dictionary Online. Oxford University Press. (http://www.oed.com/).

ICMEPS: Markus, Manfred. 1992-1997. Innsbruck Corpus of Middle English Prose Sampler. Institut für Anglistik, Universität Innsbruck. CD-ROM (https://www.uibk.ac.at/anglistik/research/projects/icamet/).

PPCME2: Kroch, Anthony, and Ann Taylor. 2000. The Penn-Helsinki Parsed Corpus of Middle English (PPCME2). Department of Linguistics, University of Pennsylvania. CD-ROM, second edition, release 4 (http://www.ling.upenn.edu/ppche/ppche-release-2016/PPCME2RELEASE-4).

PPCEME: Kroch, Anthony, Beatrice Santorini, and Lauren Delfs. 2004. The Penn-Helsinki Parsed Corpus of Early Modern English (PPCEME). Department of Linguistics, University of Pennsylvania. CD-ROM, first edition, release 3 (http://www.ling.upenn.edu/ppche/ppcherelease-2016/PPCEME-RELEASE-3).

YCOE: Taylor, Ann, Anthony Warner, Susan Pintzuk, and Frank Beths. 2003. The York-TorontoHelsinki Parsed Corpus of Old English Prose (YCOE). Department of language and Linguistic Science, University of York. CD-ROM (http://wwwusers.york.ac.uk/ lang22/YCOE/YcoeHome.htm). 
Aarts, Bas. 2007. Syntactic gradience: The nature of grammatical indeterminacy. Oxford: Oxford University Press.

Altenberg, Bengt. 1982. The genitive v. the of-construction: A study of syntactic variation in $17^{\text {th }}$ century English. Lund: Gleerup.

Anderson, Stephen R. 2016. Synchronic versus diachronic explanation and the nature of the Language Faculty. Annual Review of Linguistics 2(1), 11-31.

Biber, Douglas \& Bethany Gray. 2011. Grammar emerging in the noun phrase: The influence of written language use. English Language and Linguistics 15(2), 223-50.

Biber, Douglas \& Bethany Gray. 2016. Grammatical complexity in academic English. Cambridge: Cambridge University Press.

Breban, Tine. 2018. Proper names used as modifiers: A comprehensive functional analysis. English Language and Linguistics 22(3), 381-400. [Published online 2017]

Cristofaro, Sonia. 2017. Implicational universals and dependencies. In Nick J. Enfield (ed.), Dependencies in language: On the causal ontology of linguistic systems, 9-23. Berlin: Language Science Press.

Denison, David. 2001. Gradience and linguistic change. In Laurel J. Brinton (ed.), Historical linguistics 1999, 119-44. Amsterdam: John Benjamins.

De Smet, Hendrik. 2013. Spreading patterns: Diffusional change in the English system of complementation. Oxford: Oxford University Press.

De Smet, Hendrik, Lobke Ghesquière \& Freek Van de Velde (eds.). 2015. On multiple source constructions in language change. Amsterdam/Philadelphia: John Benjamins. [First published as Studies in Language 37(3) in 2013]

Hopper, Paul J. 1987. Emergent grammar. In Jon Aske, Natasha Beery, Laura Michaelis \& Hana Filip (eds.), Proceedings of the $13^{\text {th }}$ Annual Meeting of the Berkeley Linguistics Society: General session and parasession on grammar and cognition, 139-57. Berkeley: Berkeley Linguistics Society.

Hopper, Paul J. 1991. On some principles of grammaticization. In Elizabeth Closs Traugott \& Bernd Heine (eds.), Approaches to grammaticalization. Volume I: Theoretical and methodological issues, 17-35. Amsterdam: John Benjamins.

Joseph, Brian D. 2015. Multiple sources and multiple causes multiply explored. In Hendrik De Smet, Lobke Ghesquière \& Freek Van de Velde (eds.), On multiple source constructions in language change, 205-21. Amsterdam/Philadelphia: John Benjamins.

Kastovsky, Dieter. 1992. Semantics and vocabulary. In Richard M. Hogg (ed.), The Cambridge history of the English language. Volume I: The beginnings to 1066, 290-408. Cambridge: Cambridge University Press.

Rosenbach, Anette. 2002. Genitive Variation in English. Conceptual factors in synchronic and diachronic studies. Berlin/New York: Mouton de Gruyter. 
Rosenbach, Anette. 2006. Descriptive genitives in English: A case study on constructional gradience. English Language and Linguistics 10(1), 77-118.

Rosenbach, Anette. 2007. Emerging variation: Determiner genitives and noun modifiers in English. English Language and Linguistics 11(1), 143-89.

Rosenbach, Anette. 2010. How synchronic gradience makes sense in the light of language change (and vice versa). In Elizabeth Closs Traugott \& Graeme Trousdale (eds.), Gradience, gradualness and grammaticalization, 149-79. Amsterdam/Philadelphia: John Benjamins.

Schlücker, Barbara. 2013. Non-classifying compounds in German. Folia Linguistica 47(2), 449-80.

Traugott, Elizabeth Closs \& Graeme Trousdale. 2010. Gradience, gradualness and grammaticalization. How do they intersect? In Elizabeth Closs Traugott \& Graeme Trousdale (eds.), Gradience, gradualness and grammaticalization, 19-44. Amsterdam/Philadelphia: John Benjamins.

Van de Velde, Freek, Hendrik De Smet \& Lobke Ghesquière. 2015. On multiple source constructions in language change. In Hendrik De Smet, Lobke Ghesquière \& Freek Van de Velde (eds.), On multiple source constructions in language change, 1-18. Amsterdam/Philadelphia: John Benjamins. 